\title{
REMOTE SUZUKI'S LESSONS WITH CHILDREN ON THE AUTISM SPECTRUM
}

\author{
Kruszyńska-Szwedo J* \\ Doctoral School at the University of Silesia in Katowice, Poland
}

\begin{abstract}
The Suzuki Method defines musical abilities as not innate but one that can be developed. It is worth emphasizing that children with autism spectrum disorders could play an instrument from an early age by listening to music, imitating the game's teacher, parent, friend, repeating and perfecting songs. Key question: what is the relationship between using the Suzuki Method and developing communication skills, social competencies, and cognitive skills of students on the autism spectrum? The goal is to design a proprietary model with students in the autism spectrum based on the Suzuki Method for remote work. For the main problem, the independent variable uses the Suzuki Method with autism spectrum students aged 7 to 11 . The dependent variable results from the observational technique of student's communication skills, social competencies, and cognitive skills. An individualization experiment has been undertaken in the case study procedure. These will be case reports during the action research. A child on the autism spectrum disorder has good visual memory, developed match skills, and has the perfect pitch. Presumably, the research goals and indicators are not overestimated during Suzuki's remote lessons, too. Research can significantly accelerate reconstructive inclusion in a child.
\end{abstract}

Keywords: a child with an autism spectrum disorder, Suzuki Method, remote education, social competencies, communication skills, cognitive skills

\section{Introduction}

This article presents the Suzuki Method and demonstrates its remote use, especially in correcting, compensating, and creating a child's multilateral development. I was inspired to write this article on my musical interests and my desire to deepen my knowledge of the benefits of remote use of the Suzuki method in children with autism spectrum disorders. The main goal is to introduce the Suzuki method to parents of children with an autism spectrum to use it remotely. The research's essential aim is to encourage students of music faculties and teachers of instruments and musical subjects with higher pedagogical education - who do not know this method - to use it at a distance in their daily pedagogical work.

Musical elements (rhythm, melody, harmony, dynamics, tempo, pitch, timbre) provide various stimulation in acquiring new knowledge or skills. They introduce a space in which a child can develop. Kern and Humpal, (2013).

\section{Music in the development of children on the autism spectrum}

Kazimierz Jankowski believes that certain personality traits develop in childhood. Their presence is beneficial later in life. These include optimism, self-acceptance, and the ability to discharge tensions. 
These are overarching goals and should be considered in musical activities with children. Grzeszewski, (1998).

Musical needs are learned needs. In the absence of adequate stimulation, they may not develop at all. Particular attention should be paid to this problem in children on the autism spectrum. The emergence of musical interests may be difficult due to the limitations and lack of such activity in the centers where they stay. For music to fulfill its healing function, it must be introduced appropriately from childhood. Each properly conducted class with children should take into account three levels: "Proper use of the time devoted to making music, adapting to the child's age and disorders. Child's past - music allows you to react to negative experiences and becomes a direct therapeutic measure. A baby who becomes sedated early in development, such as lullabies, will later be susceptible to these types of sounds. The future of the child - it should be remembered that the applied musical influences will shape the child in a certain way and influence its further development." (Mazanek, 1998).

The Suzuki Method meets these expectations at all these levels. Remote communication with music by autistic children is crucial for their personal and social development. With age, playing an instrument becomes an increasingly important form of contact with this field of art. Provides the child with a capital deficit from which he can derive joy and satisfaction throughout his life.

Music makes it easier for a child with autism to gain many sensory experiences: tactile and auditory (feeling the sound produced, listening and comparing the force put into the impact, hearing and feeling the vibrations) Alvin and Warwick (1991).

Suzuki teachers are tasked with creating excellent educational conditions for children with autism spectrum, also remotely. Instrumental classes should be taught by qualified Suzuki teachers who identify new non-verbal communication methods, stimulate activity, stimulate expression, increase positive social experiences and teach correct ways to express feelings. Suzuki School should pursue general pedagogical and rehabilitation goals, also remotely. 


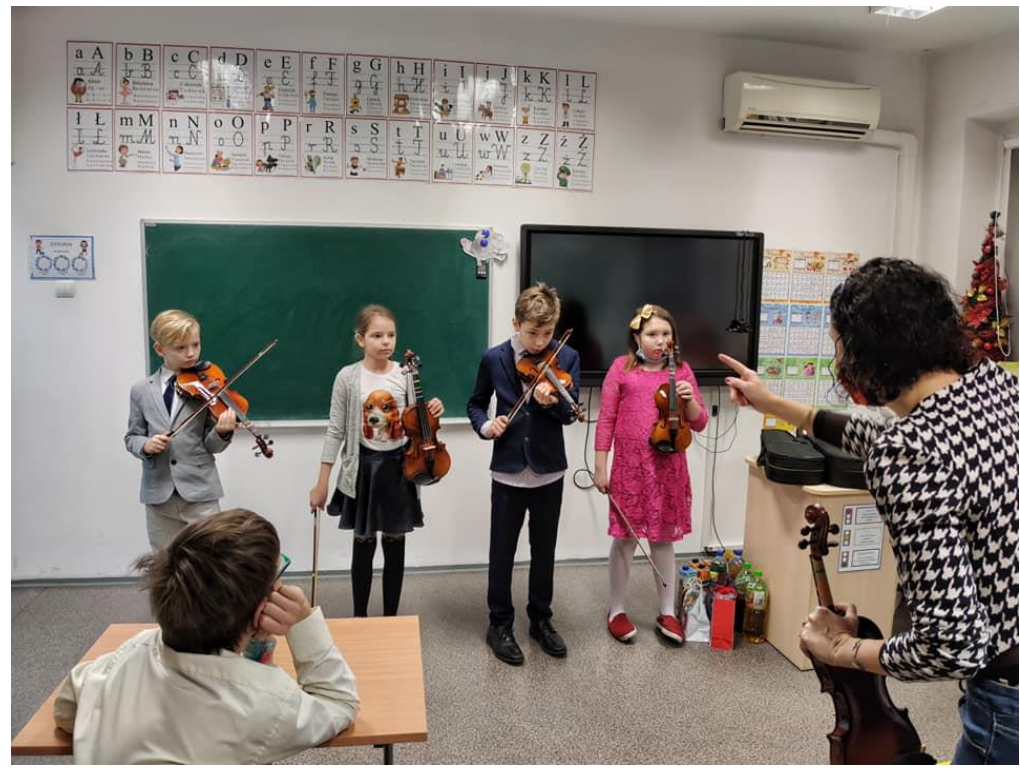

Figure 1: Suzuki Method group lessons with children with autism. Concentrate on the positions of the violins and strings. Researcher and practitioner (author of the publication) conducts Action Research in the form of voluntary work.

The goal of the Suzuki School is education and teaching. Suzuki teachers working in this way should emphasize these two terms, which imply the word "education". The priority for the teacher and parent should be to make the child a happy person. The Suzuki teacher should create positive emotions and relationships that lead to trust, mutual respect, and appropriate social behaviour modeling. Valuable information on the practical application of the Suzuki Method in working with children on the autism spectrum can be found at the link below: https://www.youtube.com/watch?v=3o8v7kYEwI4

\section{Main assumptions of the Suzuki Method}

The Suzuki Method is based on learning by listening to music and having fun. The Suzuki Method defines musical abilities as not innate but capable of being developed, similar to producing speech in the mother tongue.

"All Japanese children speak Japanese! The thought fell on me like a bolt from the blue. Since they all talk to Japanese easily and fluently, there must be a secret to it. Children all over the world are learning their mother tongue with excellent results. Why not use the same method to train other skills? I felt that I had made an extraordinary discovery. If a child cannot cope with arithmetic, his intelligence is below average. And yet, each one can very well use a complex Japanese language or another mother tongue. In my opinion, a child who cannot do arithmetic is no less intelligent; the training system is terrible. It was just that his abilities or skills had not been adequately awakened. I found it amazing that no one had figured it out before, although the whole history of humanity confirms the obviousness of this fact: the secret is in the exercise!" (Suzuki, 1983).

The author of these words is Dr. Shinichi Suzuki, violinist, educator, philosopher, and founder of the Suzuki Method.

To prove this thesis, S. Suzuki referred to the process of learning speech in the native language. "It is easy to do what we are constantly practicing. We have to practice and improve our skills, that is, do 
the same repeatedly until it becomes natural, simple, and easy for us. This is the secret" (Suzuki, 1983).

A person listening to the same $\mathrm{CD}$ every day learns the melody by ear. The same as with the language that everyone has to "get used to" before saying the first "mom and dad." Regardless of the objective difficulties that this language presents (accents, dialect), every child learns it ideally by imitating their parents.

The mechanism above can be transferred to the music education of people with special needs. Therefore, it is worth emphasizing that people on the autism spectrum can learn to play an instrument from an early age by listening to music, imitating the game (teacher, parent, friend), repeating and correcting songs. Then the music around them is part of them. Playing becomes as "simple" as speaking. Hence the name "mother tongue method."

Initially, the research concerned only the violin, as the initiator of this method was the Japanese violinist and teacher Shinichi Suzuki. Because it produced excellent results, it quickly spread to other instruments.

The goal of the Suzuki Method is to learn and develop skills, not the perfect musician. Teaching early music influences the development of other skills, including linguistic, math, and manual skills. It improves hand-eye coordination, memory, and perceptiveness. The child learns to cooperate with other people, focus on the task at hand, self-discipline, and regular work on achieving the set goals, which is very important for the future learning at school and in adult life. The Suzuki Method is helpful in inclusive education for this group of children. It is worth looking for its positive impact on correcting disturbed functions, reducing psychophysical tensions, and providing beneficial social experiences. As a result of the above actions, the method improves mood, relieves stress, and improves group members' relationships.

\section{Music and its importance in the therapy process - research review}

In recent years, there has been tremendous growth in aesthetic education worldwide, including music education and therapy through the arts. "The aesthetic level of music concerns the effects that the music produces. It does not appeal to the intellect but directly to the feelings and even borders on the senses' realm. The problem of effectiveness concerns the degree to which the obtained acoustic and semantic symbols brought about the desired effect. This applies equally to emotional (emotional, psychological) and sensory (e.g., motor) reactions and physiological reactions of the body, which are near related to them. It is about the so-called musical expression received and transmitted, ie. emotions and moods arise under the influence of music or are they as if "designed" by the recipient for the piece they are listening to. Experience shows that a sad listener, under the influence of cheerful music, cheers up, and under the influence of melancholic music, the mood of a nice person lowers. Therefore, it can be said that music evokes specific reactions" (Natanson, 1976). "Scientists have managed to locate the center that directs the feelings evoked by music. The research consisted of the emotional evaluation of sharp rock, pop, jazz, and classical sequences. Sounds perceived as beautiful stimulated the temporal and frontal areas of the brain's left hemisphere" (Jaborska, 2004).

At the stage of distance education with children on the autism spectrum, various forms of art therapy can be successfully used; one such form may be the Suzuki method. It is worth searching for its 
usefulness in the education and treatment of the discussed group of children to correct disturbed functions, reduce psychophysical tensions and provide beneficial social experiences. The therapeutic effect covers the entire psychophysical organism, particularly emotions, aspirations, expectations, and dreams. Author of the article noticed that as a result of conducting group classes in playing an instrument with a therapeutic and educational effect. Dr. Shinichi Suzuki's Method improves wellbeing, removes anxiety, relieves tension, and improves group members' relationships.

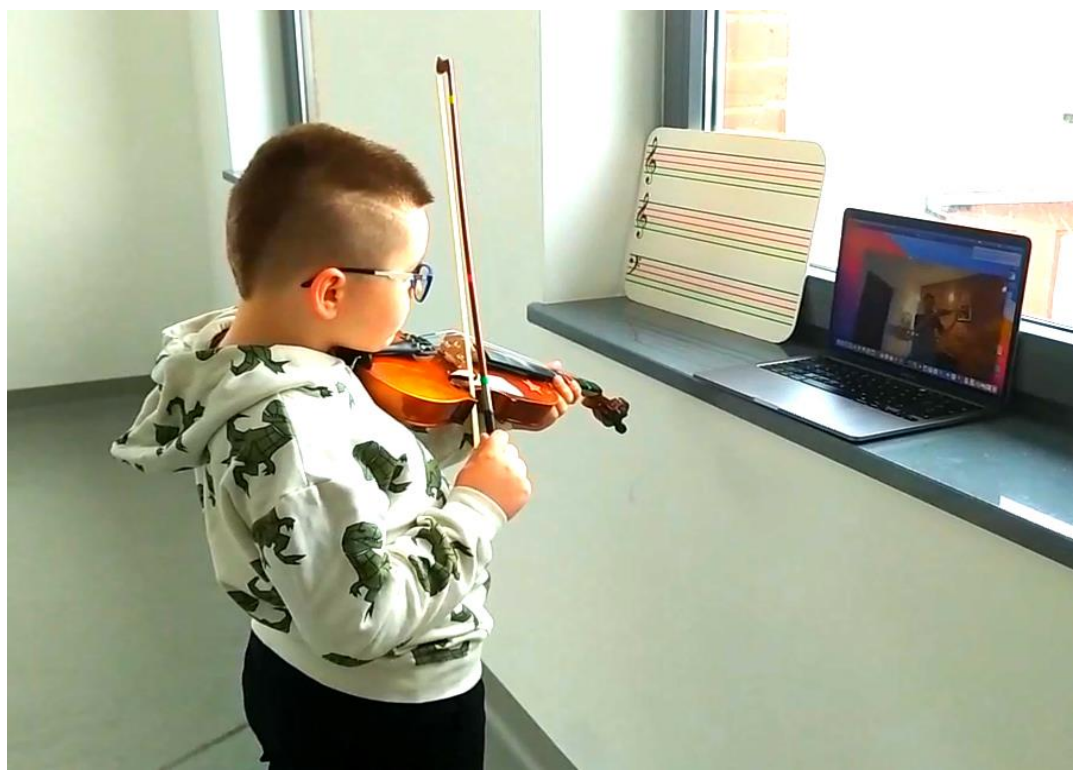

Figure 2: Remote lesson. Practicing graphomotor skills. Place the bow on the E and A strings

"Music is an area of upbringing and education on which the multifaceted mental development of a child depends. Since art consists of sounds, it evocatively influences the imagination and enriches individual sensations and experiences, both emotional and intellectual. Through contact with music, the child gradually acquires musical knowledge that spontaneously shapes his attitude to this field. Music sensitivity causes positive changes in the overall development of a child. It affects musical abilities and versatility; it shapes the general mental and emotional, cognitive, and social spheres. Therefore, music has an accessible educational value and plays an essential role in education and upbringing" (Szczepańska, 2004).

The author of Psychology of Music, Jerzy Wierszyłowski, points out that research into music's educational function in schools shows that properly conducted music education produces several significant educational effects. He also refers to the opinion of the director of the Tokyo Academy of Music, N. Fakuya, who stated that musical education helps in the physical development of a child, develops the ability to form a concept, form, structure, volume, views around the world, socializes itself through participation in the group's work and concentration of attention.

Wierszyłowski believes that: "the broadly understood creative ability, which is the most important factor of intelligence, shaped basically on the musical material, is then used in other areas of life not related to art" (Wierszyłowski, 1979). Understanding this fact meant that this concept of musical activity, called music education, was taken very seriously in many countries, entrusting the development of methods, musical materials, and teaching to special scientific institutes. 


\section{The Suzuki method as an innovative approach to therapy}

The basic tenet of the Mother Tongue Method is that all children are born gifted. As S. Suzuki wrote, "the right environment favors talent. There is no need to look for innate abilities or skills. This environment has the most significant impact on developing talents" (Suzuki, 1983). Dr. Suzuki's method has gained international recognition. It is propagated in many centers in the United States, at the prestigious Julliard School of Music and many others.

One of the most critical assumptions of the method is to ensure the development of any child who must be adequately cared for and educated.

Music can have a many-sided influence on the psyche and the vegetative functions and activities of individual functional systems. Music lessons can be in groups or individually. Suzuki teachers devote all their energies to promoting talent education for children with disabilities. What a child becomes in the future depends on how we raise him or her.

One of the discussed method's critical assumptions is intensive cooperation with parents, necessary for remote lessons. The emotional authority in the educational sense of the child is the parent. Therefore, we first teach the mother/father to be a good home teacher. In the beginning, the child only listens to the song to be learned. One of the parents must undergo training to teach the child the correct posture and positioning of the hands. Proper education depends on it. As long as the parent cannot play even one song, he does not get the instrument. This is very important as a three- or fouryear-old child may not want to play an instrument even though parents do. The child himself has to say, "I want to play too." The first track is played every day from the CD at home, and at school, the child watches his friends and parents play. This creates the right atmosphere. Mother/father plays the instrument at home and school as part of the training. At some point, the child will ask the mother/father for a violin and start playing. He already knows the melody. He sees his friends having a good time and wants to be a part of it too. The parent's authority is smoothly expanded with references based on the teacher's knowledge and improved skills. Suzuki's teacher and his parent made him thirsty. The first individual game lesson evokes excellent emotions.

There are individual and group lessons at school. Parents who understand children are excellent teachers. Playing in a group with advanced children greatly stimulates their development. This is genuine talent education and is a priority of the Suzuki Method. The Suzuki teacher teaches with joy and willingness that the children's learning approach is played with therapeutic-artistic impact. Apart from being a strict teacher, it can easily discourage a child. This is the right course of study. For both the Suzuki teacher and the parent, it is vital that the child masters the skill. This school is based on a natural and straightforward method, where you first need to prepare your child and then start practicing skills mentally.

This Suzuki Method's regularities have incredibly positive effects on building and participating in social relationships and communicating remotely. From personal observations during action research, it appears that disorders in social communication and limited patterns of behaviour, activity, and interests are supplemented thanks to active participation in classes to play the instrument conducted with the Suzuki Method. Dr. S. Suzuki's method is used for communication in the educational and upbringing space. In a favorable play atmosphere, the child learns positive social behaviour, kindness towards others, and joint performance responsibility. In the first years, contact with the Suzuki 
Method gives excellent results and the ability to alternate participation in interactions, including initiating and maintaining communication.

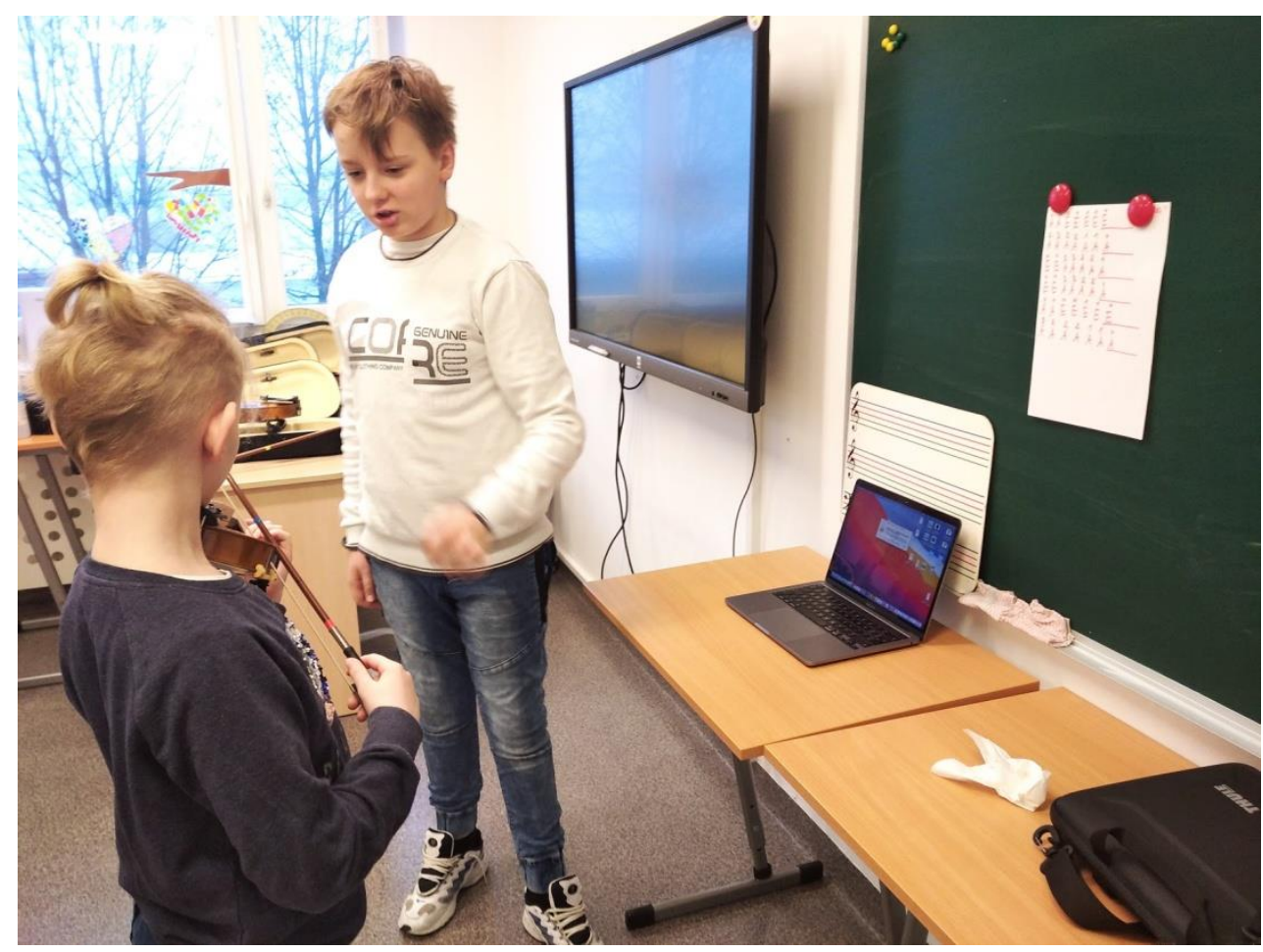

Figure 3: Social interactions during remote group lessons.

The diagnostic value of early, occurring in the first years of children's life, abnormalities in social development and communication is undoubtedly essential to overcome these deficits. A diagnosis that may be made later in the child's life does not prejudge the Suzuki Method's added value.

In terms of social relationships, behavioural indicators thanks to the Suzuki Method include spontaneous sharing of interests (playing songs in front of parents and making music together.) The ability to read emotions based on a Suzuki CD song and use these skills to regulate their behaviour (the child tries to play the piece in response to the mother/father). The Suzuki Method enriches the expression of affection and interest in other children in this group activity. The Suzuki method has a positive effect on speech development; the child repeats other people's statements, understands their content, and strives to communicate. There is a progress in action, which initially manifests itself in the field of communication (the child imitates the movements appropriate to a particular instrument, in the case of a violin, these are "string" and "violin" movements, he speaks "musically" on the device to play during group activities). Thanks to the Suzuki Method and participation in individual and group activities, children's specific interests and play patterns on the autism spectrum become visible.

The most significant advantages of remote lessons using the Suzuki Method, which a child on the autism spectrum learns during individual and group classes, consist in the readiness to establish social relationships and greater interest in social stimuli and typical response to them (e.g., calling the child by name, using eye contact and expression mimic in situations of the presence of emotional synchrony and rich vocalization). Added value Suzuki methods also include the ability to imitate, create a common field of attention and show affection for loved ones. 
When participating in remote activities using the Suzuki Method, typical patterns of play and interests draw attention. Many of these regularities are noticed by parents; some can also be relatively easily observed in the child's behaviour. The tools used during action research are based on direct observation of the child's behaviour.

The article is an encouragement, above all, for parents of children on the autism spectrum to use the Suzuki Method, also remotely, which has measurable benefits and advantages (understood in terms of therapy through music). The author of the article (researcher and practitioner) adopted the concept that the Suzuki Method is the starting point for exploring and developing children's abilities, striving for their full personality development. It is useful in mastering musical skills and transferring them to other disciplines.

\section{Conclusion}

Music as a form of art accompanies man from the dawn of his history. It has always served to discharge and externalize emotions, improve mood, relax, or even encourage to fight, motivated to act. For many centuries, music has been spontaneously woven into human life. It was only relatively recently that its therapeutic effects began to be noticed, analyzed, and used systematically, purposefully, and more scientifically.

Music has a strong and positive effect on children with deficits. The reception of elementary parts of music such as rhythm and tempo positively impacts their functioning. It is especially noticeable in the social and emotional sphere. Music has a natural healing effect on disturbed spheres.

Taking musical activities as a play by children makes its positive impact stronger.

In light of the above facts, I consider it necessary to promote the Suzuki Method among children with deficits, especially in a remote form. Each child will be provided with appropriate care and education. The aim of teaching using the Mother Tongue Method is comprehensive development, sensitizing him to beauty, and building self-esteem. "Talent is life.[...] Vital forces stimulate the human species. Living and wanting to live, the being reveals tremendous possibilities by adapting to the environment. Man develops vitality and shows different talents depending on the environment. They allow them to overcome all difficulties, grow and transform into outstanding abilities in constant patience. It is not enough to think and theorize alone to develop talent; action, practice is needed" (Suzuki, 1983).

\section{Discussion}

The article presents the fundamental aspects of upbringing and teaching - which imply the word "education" - through the Suzuki Method in children on the autism spectrum. According to the principle, the method should be used for every child, expecting and observing measurable benefits. Sensitization to music through participation in individual and group classes causes positive changes in the child's overall development on the autism spectrum, influencing the emotional, cognitive and social sphere, shaping the general mental level. The therapeutic effect included improving psychophysical functioning, the quality of communication, and social interaction in children on the autism spectrum, which are significant benefits of the Japanese teaching method. 


\section{References}

Alvin, J., Warwick, A., (1991). Music Therapy for the Autistic Child, Oxford University Press, New York;

Grzeszewski, H. (1998). Muzyka w wychowaniu i terapii dziecka niepełnosprawnego. Szkoła Specjalna, nr 5, 153;

Jaborska, E. (2004). Muzykoterapia w szkole. Nauczyciel i Szkoła, nr 1-2 (22-23), 265-285;

Kern P., Humpal M. (2013). Strategies and Techniques. Making it Happen for Young Children with Autism Spectrum Disorders, [w:] Early Childhood Music Therapy and Autism Spectrum Disorders. Developing Potential in Young Children and their Families, P. Kern, M. Humpal (red.), Jessica Kingsley Publishers, London-Philadelphia;

Kruszyńska-Szwedo, J. (2020). Figures: 1, 2, 3. Private collection;

Mazanek, E. (1998). Dziecko niepełnosprawne ruchowo. [w:] cześć III, Wychowanie i nauczanie dzieci z mózgowym porażeniem dziecięcym, Warszawa, Wydawnictwa Szkolne i Pedagogiczne;

Natanson, T. (1976). Wstęp do nauki o muzykoterapii. Wrocław, Ossolineum;

Niebieski Zakątek. (2021, January 27) Niebieski Zakątek Chorzów - Nauka przez zabawę!. [Video file]. Retrieved from https://www.youtube.com/watch?v=3o8v7kYEwI4;

Suzuki, S. (1983). Nurtured by Love: The Classic Approach to Talent Education. Miami, Warner Bros;

Szczepańska, A. (2004). Zajęcia muzyczno-ruchowe w edukacji wczesnoszkolnej. [w:] Ekspresja twórcza dziecka. Konteksty- inspiracje- obszary realizacji. Katowice, Librus;

Wierszyłowski, J. (1979). Psychologia muzyki, Warszawa, PWN. 